\title{
Comprehensive Brand Effect: A Data of Automobile Brands
}

\author{
YANG Yi-weng ${ }^{1, a^{*}}$, XV Yan ${ }^{1, b}$, TU Jian-bo ${ }^{1, c}$ and JI XUE-hong ${ }^{1, d}$ \\ ${ }^{1}$ School of Economics and Management, North China University of Technology, Beijing 100144, \\ China \\ akevingeorgehenry@163.com, bbnuxuyan@126.com, ctujianbo19820416@163.com, \\ dixuehong86@163.com
}

Keywords: product brand; corporate brand; country brand; comprehensive brand effect; automobile brand

\begin{abstract}
Chinese Brands are large but not strong, and China lacks true global brands. Product, corporate, and country brand are all of crucial important to building Chinese global brands. A survey on Chinese consumers is conducted to examine their attitudes and purchase intentions toward five automobile products of five corporations which come from five countries. The results indicate that both product band and country brand positively affect corporate brand and the impact of product brand is stronger; the impact of product brand on purchase intention is significant but country brand has no direct influence on purchase intention; corporate brand firstly influences attitude and then affects purchase intention; the strongest impact on purchase intention is attitude toward corporate brand, then product brand and country brand. The paper further enriches the relevant theory of brand and provides managerial implications for building Chinese global brands.
\end{abstract}

\section{Introduction}

In recent years, China's economy has been growing rapidly, and the scale of China's multinational corporations (MNCs) also expands accordingly. But the more common view is that Chinese brands are large but not strong, and China lacks true global brands. How to build Chinese global brands? We can deal with this problem from micro (product brand), meso (corporate brand), and macro (country brand) perspective. Firstly, product brand remains important. Consumers often perceive one brand from its product attributes at first. According to an Interbrand's report, the most serious problem of Chinese brands is still product quality issues. Secondly, corporate brand has more important significance under the context of Chinese culture. Influenced by collective and family-oriented self-construction, Chinese consumers mainly follow the thinking mode of "corporate $\rightarrow$ product" when they make decisions. Thirdly, country brand is becoming increasingly important. The overall brand image of a country is a strategic competition resource. For example, MNCs from the U.S., France and Germany can often enjoy brand premium when they undertake global marketing. While the overall image of Chinese brands is unfavorable, and especially difficult to compete for the high-end positioning in the minds of international consumers. In conclusion, product, corporate, and country brand are all of crucial important to building Chinese global brands. However, so far, little attempt has been made to study their relations and their comprehensive brand effect on consumer decision, this is the research gap the present paper attempts to fill. 


\section{Literature Review}

Product Brand. Brand refers to "the name, term, design, symbol, or any other feature that identifies one seller's product distinct from those of other sellers" (American Marketing Association). This definition is mainly targeted at product, so it can be used as the definition of product brand. Dodds et al. (1991) stated that product brand and store information positively influence perceived quality, perceived value, and purchase intention ${ }^{[1]}$. Godey et al. (2012) tested the combined effect of product brand and country-of-origin on purchase decision, and found that the impact of product brand is stronger ${ }^{[2]}$. Grewal et al. (1998) advanced the research route as follow: product brand name $\rightarrow$ perceived brand quality $\rightarrow$ perceived value $\rightarrow$ purchase intention ${ }^{[3]}$.

Corporate Brand. King (1991) put forward the definition of corporate brand for the first time ${ }^{[4]}$. Corporate brand refers to "the name, term, design, symbol, or any other feature that identifies one seller distinct from those of other sellers". Brown and Dacin (1997) demonstrated: (1) what consumers know about a company can influence their beliefs about and attitudes toward new products manufactured by that company; (2) corporate ability and corporate social responsibility associations have different effects on consumer responses to products; (3) products of companies with negative associations are not always destined to receive negative responses ${ }^{[5]}$. Similarly, most of the existing researches are focus on the impact of corporate image (corporate association) on consumer evaluation, attitude, purchase intention, and so on from the consumer perspective.

Country Brand. The researches on country brand originate from the country-of-origin research conducted by Schooler $(1965)^{[6]}$. Country-of-origin is "the country or region where a product comes from". Country-of-origin is an objective reality, while country-of-origin image is a kind of subjective perception. Country-of-origin image is "consumer's overall perception of a certain country or region". Researches eventually focus on the effect of this kind of perception on consumer decision. Country-of-origin effect is "the psychological effect describing how consumers' attitudes, perceptions and purchasing decisions are influenced by products' country-of-origin image". Some scholars put forward the conception of country brand from the brand perspective. Country brand is "a country's whole brand image, covering political, economic, historical and cultural dimensions". Lots of studies have confirmed that country brand has positive impact on consumer evaluation, attitude, purchase intention, and so on ${ }^{[7]}$. Many researches pointed out that some moderators and mediators exert influence on country-of-origin effect.

Comprehensive Brand Effect. Hsieh et al. (2004) found that while consumers' attitudes toward corporate and country image exert main effects on their brand purchase behavior, the effects of certain product image appeals are moderated by socio-demographics and national cultural characteristics $^{[8]}$. Wang et al. (2012) demonstrated that cognitive and affective country image have different impacts on the intention to purchase, with the former influence purchase through product image, and the latter having a direct influence, independent of product image ${ }^{[9]}$. Fan (2011) tested the relations among product, corporate, and country brand, as well as their impact on consumer brand attitude and purchase intention ${ }^{[10]}$. But this research only tested one product (washing machine) of one corporation (Haier), which comes from one country (China). This makes it impossible to compare the differences among different products of different corporations, which come from different countries.

Based on the above literature review, this paper argues that most of the existing literatures study the impact of product, corporate, or country brand on consumer decision alone in their respective fields, few consider two of them at the same time. Just one research studies the relations among all the three, as well as their comprehensive brand effect on consumer decision, but there are some 
limitations in its research method, which leads to its incomprehensive research conclusions. Faced with the problems mentioned above, this paper puts forward research hypotheses as follow.

\section{Research Hypotheses}

Most of Apple's great success in recent years can be attributed to its releases of star products like iPod, iPhone, iPad, and so on. Because the most direct way consumers perceived a corporation is to use or experience its products, so product attributes such as design, quality, price, and so on are the most direct and critical influence factors of corporate image. So, this paper proposes:

H1: Product brand will positively affect corporate brand.

Fan (2011) found that country image has positive impact on corporate image; country image can also indirectly influence product image through corporate image ${ }^{[10]}$. Hsieh (2004) reported that country brand exerts influence on corporate brand through its "halo effect" ${ }^{[8]}$, that is, when consumers like one country, they will fall in love with corporations and products coming from that country. So, this paper proposes:

H2: Country brand will positively affect corporate brand.

Brown and Dacin (1997) suggested that corporate association contains two dimensions: corporate ability and corporate social responsibility, and those two dimensions have different effects on consumer responses to products ${ }^{[5]}$. Based on this, this paper derives:

H3: Corporate brand will positively affect consumer attitude.

Chung et al. (2009) reported that product brand image has stronger effect than country-of-manufacture on Koreans' attitude and purchase intention of hybrid global products ${ }^{[1]}$. So, this paper proposes:

H4: Product brand will positively affect purchase intention.

Hsieh et al. (2004) found that corporate and country brand exert positive main effect on consumer brand purchase behavior ${ }^{[8]}$. Peterson and Jolibert (1995) reported that the average effect of country-of-origin on purchase intention is $.19^{[7]}$. Wang et al. (2012) demonstrated that cognitive and affective country image have different impacts on purchase intention ${ }^{[9]}$. In the light of the above, this paper derives:

H5: Country brand will positively affect purchase intention.

Fishbein and Ajzen (1975) suggested that consumer perception of design, quality, price, and other product attributes exerts influence on the formation of consumer attitude ${ }^{[12]}$. On the basis of the Fishbein model, Mitchell and Olson (1981) proposed the following research route: consumer's attitude toward advertisements and belief in product attributes $\rightarrow$ consumer's attitude toward brand, purchase, and brand using behavior $\rightarrow$ consumer behavior intention ${ }^{[13]}$. So, this paper proposes:

H6: Consumer attitude will positively affect purchase intention.

\section{Method}

Based on the above hypotheses, this research chooses automobile brands to conduct data collection. The five automobile brands we adopted are: Germany VW Magotan, the U.S. GM Regal, Japan Honda Accord, Korea Hyundai Sonata, and China FAW Besturn. A combination of web survey and field survey is employed to collect data. The website we used is: http://www.askform.cn, respondents are students who come from a driving school in Hunan province. The field survey is undertaken in accumulation areas of the five automobile brands' $4 \mathrm{~S}$ stores locating in Beijing. Participants are potential consumers who have demands for automobiles or owners who have car-buying experiences, so the external validity is better than researches using student samples. The 
questionnaire survey begins on June, 2014; ends on August, 2014. We distribute 600 questionnaires, take back 357 valid questionnaires; the valid response rate is 59.6\%. Participants are randomly assigned to answer survey questions on one of five countries (70 respondents or $19.6 \%$ of the sample on Germany; 73 or $20.4 \%$ on U.S.; 71 or $19.9 \%$ on Japan; 71 or $19.9 \%$ on Korea; and 72 or $20.2 \%$ on China). Appropriate scales for the focal constructs are identified after a careful review of the pertinent literature, which in previous research have been generally found to be reliable and valid. All items except demographic information are measured on a 5-point Likert-type scale form "strongly disagree" (1) to "strongly agree" (5). This research uses Cronbach's $\alpha$ and composite reliability (CR) to test the reliability of the scales; uses confirmatory factor analysis (CFA) to test the validity of the scales; uses structural equation modeling (SEM) to verify hypotheses in the model; and uses ANOVA to do multiple comparisons.

\section{Analysis and Results}

Reliability and Validity Analysis. The Cronbach's $\alpha$ of the whole scales is: .908, the Cronbach's $\alpha$ of product brand, country brand, corporate brand, attitude, and purchase intention are: $.892, .822, .792, .754$, and .787 , respectively (above .7). The CR value of product brand, country brand, corporate brand, attitude, and purchase intention are: .894, .828, .806, .786, and .798, respectively (above .7). All the above indicates that the reliability of the scales is good. The average variance extracted (AVE) value of product brand, country brand, corporate brand, attitude, and purchase intention are: $.678, .619, .517, .568$, and .573 , respectively (above .5 ), which shows that the convergent validity of the scales is good. Every construct's square root of AVE value is greater than its Pearson correlation coefficient with other constructs, which shows that the discriminant validity of the scales is good. All the above shows that the reliability and validity of the scales are good, we can use SEM to do hypothesis testing further.

Hypothesis Testing. This research uses the chi-square value estimated by Bollen-Stine Bootstrap 5,000 times to modify the overall model fit, and all goodness-of-fit indices are listed in Table 1. Except that the SRMA is greater than the recommended .05, others are all at acceptable range, which suggest that the fitness between model and the observed data in this study is acceptable.

Table 1 Model Fit Test

\begin{tabular}{lcccccccccc}
\hline Goodness-of-Fit Indices & $\chi^{2}$ & $\mathrm{df}$ & $\chi^{2} / \mathrm{df}$ & GFI & AGFI & SRMA & RMSEA & CFI & NNFI & IFI \\
\hline Test Results & 128.885 & 112 & 1.151 & .964 & .943 & .096 & .021 & .995 & .994 & .995 \\
Acceptable Levels & & & $1 \sim 3$ & $>.9$ & $>.9$ & $<.05$ & $<.08$ & $>.9$ & $>.9$ & $>.9$ \\
\hline
\end{tabular}

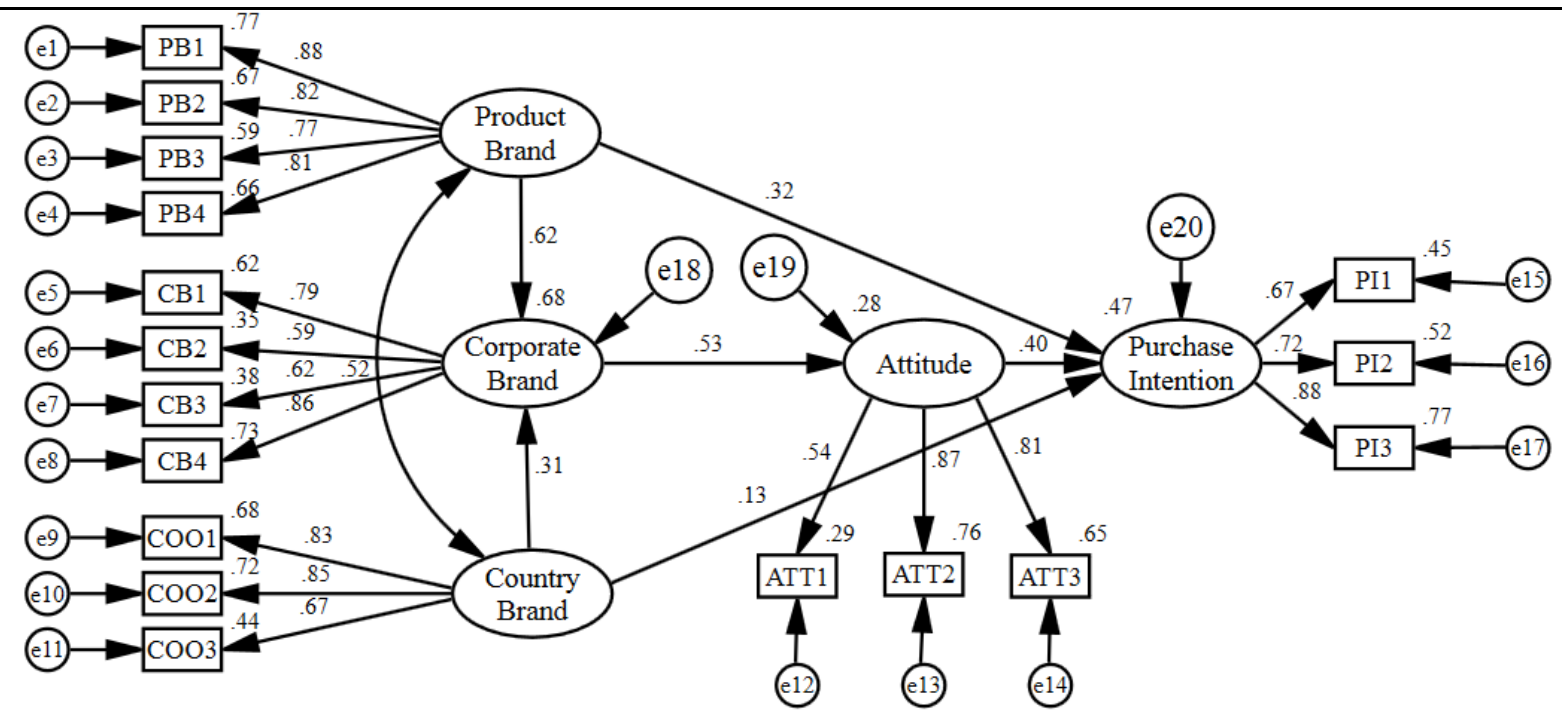




\section{Fig. 1 SEM Test Results}

As shown in Fig. 1, we report the results as follow. (1) In terms of the standardized estimates. All the variances and residuals are positive value and significant, all the factor loadings are above the acceptable lever (.5). (2) In terms of the unstandardized estimates. The results indicate that $\mathrm{H} 1$, $\mathrm{H} 2, \mathrm{H} 3, \mathrm{H} 4$, and $\mathrm{H} 6$ are supported, but surprisingly, H5 is not supported. (3) In terms of the standardized estimation. R-square value of corporate brand is .68 , which shows that $68 \%$ of corporate brand's information can be explained by product and country brand (R2>0.67, strong explanation); the standardized path coefficients show that the impact of product brand on corporate brand is stronger than country brand $(.62>.31)$. R-square value of attitude is .28, which shows that $28 \%$ of attitude's information can be explained by corporate brand ( $\mathrm{R} 2<0.33$, medium weak explanation). R-square value of purchase intention is .47 , which shows that $47 \%$ of purchase intention's information can be explained by product brand, country brand, and attitude toward corporate brand $(.33<\mathrm{R} 2<.67$, medium explanation); the standardized path coefficients show that the strongest impact on purchase intention is attitude toward corporate brand, then product brand and country brand $(.40>.32>.13)$. (4) We use One-Way ANOVA to test the differences of product brand, country brand, corporate brand, attitude, and purchase intention among the five automobile products of five corporations which come from five countries, the results show that there exist significant differences. Combined with Tukey method, Fisher method, Dunnett method, and Hsu's MCB Method, we test the specific differences. The results are similar and indicate that although the country brand of Japan receives the lowest rating among the five countries, the corporate brand of Honda ranks No. 3 among the five corporations. This is because product brand also impacts corporate brand and its impact is stronger than country brand (Accord ranks No. 3 among the five automobile products). Consumers' purchase intention of Accord also ranks No. 3 among the five automobile products, this is because the strongest impact on purchase intention is consumer attitude toward corporate brand, then product brand and country brand; in addition, the direct impact of country brand is not significant.

\section{Conclusion and Discussion}

Conclusion. This paper finds: (1) both product brand and country brand have significant positive impact on corporate brand, and the impact of product brand is stronger; (2) product brand significantly influences purchase intention directly, but the direct impact of country brand on purchase intention is not significant, country brand can only impact purchase intention indirectly through corporate brand; (3) corporate brand influences consumer attitude at first, and then purchase intention; (4) the strongest impact on purchase intention is consumer attitude toward corporate brand, then product brand and country brand. These findings further enrich the relevant theory of brand, and hold direct and important managerial implications.

Managerial Implications. Firstly, this paper finds that Chinese consumers are most inclined to buy Magotan and Regal. Both durable German cars and comfortable American cars are popular among Chinese consumers. Accord is in the second class. In the survey process, lots of consumers expressed that although the quality of Japanese cars were not worse than German and American cars, and were more fuel-efficient, they would never buy Japanese cars due to historical and political reasons. Studies have found that consumer animosity toward special countries influences country brand effect. So when marketing in the Asian market, Japanese brands should highlight their "Asian brand" image, and dilute the country brand of Japan. Studies have found that consumer bias can be eliminated to a certain extent by using region brand rather than country brand. It is also enlightening for Chinese brands to expand the Japanese market. Sonata and Besturn are in the third 
class. Surprisingly, the popularity of Chinese cars is as good as Korean cars; this may be due to the patriotism of Chinese consumers. Studies have reported that consumers with high patriotism may prefer domestic products, and ignore the differences of country brand images and quality of products. So, when marketing in the domestic market, Chinese brands should make the best of consumer patriotism.

Secondly, the most influential brand ranking lists in the world at present are Interbrand's "Best Global Brands" and World Brand Lab's "the World's 500 Most Influential Brands", both those two lists rank brands based on corporate brand, so building and maintaining strong corporate brand is of critical importance to build Chinese true global brands. How to do it? This paper shows that $68 \%$ of corporate brand's information can be explained by product and country brand, providing strong explanation; and compared to country brand, the impact of product brand on corporate brand is stronger. According to an Interbrand's report, the most serious problem of Chinese brands now is still "low-quality reputation". Based on the findings of this paper, China's MNCs should try hard to improve the quality of products at first. Because product brand not only influences purchase intention directly but also influences corporate brand. Furthermore, country brand exerts significant positive impact on corporate brand, which indicates that Chinese MNCs should join up with industrial clusters and the Chinese government to devote themselves to reversing the unfavorable stereotypes of Chinese brands in the minds of international consumers together, rather than walk alone.

Thirdly, this paper finds that the direct impact of country brand on purchase intention is not significant. Lots of studies have found that the country brand effect will weaken when product and country brand information are available for consumers at the same time. Moreover, with the rapid expansion of Chinese MNCs' scale, Chinese brands are becoming more and more famous. Previous studies have demonstrated that with the increase of consumer brand familiarity, consumers will increasingly be dependent on product and corporate brand information to make decisions, rather than just consider which country the products come from. Participants of this research are potential consumers and actual cars owners, so they are familiar with major automobile brands, and make decisions based more on product and corporate brand than country brand. This leads to the non-significant direct impact of country brand on purchase intention. Finally, automobile industry is a mature industry in China. Studies have showed that in the mature period of product life cycle, the impact of country brand on consumer decision tends to fall because consumers are very familiar with the product. The results are actually good news for Chinese brands with unfavorable country brand image, on the basis of high brand awareness, Chinese brands should try hard to improve brand favorite next, rather than keep making "low-cost low-quality" products at the bottom of the "Smiling Curve". Only in this way can Chinese brands compete for the high-end positioning in the minds of international consumers, and win abundant brand premium eventually.

\section{Limitations and Directions for Future Research}

First, this paper studies the comprehensive brand effect from the consumer perspective, future researches can extend it on the corporate lever. For example, scholars could study the impact of product, corporate, and country brand on brand equity, corporate performance, and so on. Second, all the data used in this paper come from automobile brands, automobile is a high-involvement durable product, future studies could use data coming from other product categories (such as low-involvement products) and service (such as tourism, consulting, and so on) to further verify and extend findings of this paper. Third, the sample of this research is confined to Chinese consumers, but the perceptions of the same brand may differ among consumers coming from diverse countries, 
future researches could use samples from a number of countries to do cross-national and cross-cultural research (such as: developed countries vs. developing countries; collectivism countries vs. individualism countries).

\section{Acknowledgment}

The author would like to acknowledge the support of the Humanities and Social Sciences Foundation of Ministry of Education of China (No. 14YJC630167), the Scientific Research Starting Foundation of North China University of Technology (No. 14HENRY0020), the Outstanding Young Teachers Training Program of North China University of Technology (No. 14085), and the Excellent Researchers Award Program from Beijing Organization Department (No. 401053711405).

\section{References}

[1] W.B. Dodds, K.B. Monroe, D. Grewal, Effects of price, brand, and store information on buyers' product evaluations, Journal of Marketing Research 28 (1991) 307-319.

[2] B. Godey, D. Pederzoli, G. Aiello, et al., Brand and country-of-origin effect on consumers' decision to purchase luxury products, Journal of Business Research 65 (2012) 1461-1470.

[3] D. Grewal, R. Krishnan, J. Baker, et al., The effect of store name, brand name and price discounts on consumers' evaluations and purchase intentions, Journal of Retailing 74 (1998) 331-352.

[4] S. King, Brand-building in the 1990s, Journal of Marketing 7 (1991) 3-13.

[5] T.J. Brown, P.A. Dacin, The company and the product: corporate associations and consumer product responses, Journal of Marketing 61(1997) 68-84.

[6] R.D. Schooler, Product bias in the Central American Common Market, Journal of Marketing Research (1965) 394-397.

[7] R.A. Peterson, A.J. Jolibert, A meta-analysis of country-of-origin effects, Journal of International Business Studies 26 (1995) 883-900.

[8] M.-H. Hsieh, S.-L. Pan, R. Setiono, Product-, corporate-, and country-image dimensions and purchase behavior: a multicountry analysis, Journal of the Academy of Marketing Science 32 (2004) 251-270.

[9] C.L. Wang, D. Li, B.R. Barnes, et al., Country image, product image and consumer purchase intention: evidence from an emerging economy, International Business Review 21 (2012): 1041-1051.

[10]Q.J. Fan, The relationship among China's country image, corporate image and brand image: a perspective of Korean consumers, Journal of Marketing Science 7 (2011) 99-114.

[11] J.-E. Chung, D.T. Pysarchik, S.-J. Hwang, Effects of country-of-manufacture and brand image on Korean consumers' purchase intention, Journal of Global Marketing 22 (2009) 21-41.

[12]M. Fishbein, I. Ajzen, Belief, attitude, intention, and behavior: an introduction to theory and research, Addison-Wesley, Boston, 1975.

[13]A.A. Mitchell, J.C. Olson, Are product attribute beliefs the only mediator of advertising effects on brand attitude?, Journal of Marketing Research 18 (1981) 318-332. 